\title{
Improved Preservation of Saphenous Venous Conduits by the Use of Papaverine mixed heparinized blood Solution during Harvesting
}

\author{
MF Maruf ${ }^{1}$, SAMA Sabur ${ }^{2}$, T Akter ${ }^{3}$, E Hakim ${ }^{4}$, NAK Ahsan ${ }^{5}$ \\ ${ }^{1}$ Assistant Professor, Cardiothoracic Surgery, Chittagong Medical College, ${ }^{2}$ Associate Professor, \\ Cardiothoracic surgery, NICVD, ${ }^{3}$ Assistant Registrar,cardiac Surgery, NICVD, ${ }^{4}$ Assistant professor, \\ vascular surgery, NICVD, ${ }^{5}$ Professor \& Head (Ex), Cardiothoracic Surgery, NICVD, CMC.
}

Key Words:

Venous Grafts, $C A B G$,

Papaverine

\begin{abstract}
:
Background: High-pressure distension during harvesting damages the saphenous vein (SV) and may contribute to subsequent coronary artery bypass graft (CABG) occlusion. Application of vasodilator agents to the SV during harvesting may reduce the need for high-pressure distension and improve graft quality. We tested the effects of a vasodilator solution containing the conventional agent papaverine (Pap) mixed with heparinized blood on the pressure necessary to overcome $S V$ spasm and on the structure.

Methods: 150 patients undergoing $C A B G$ were nonrandomly allocated to receive an application of either intraluminal papaverine (Pap) mixed with heparinized blood(Group-A), or intraluminal heparin mixed normal saline(group-B) to the $S V$ for distension during harvesting. The peak pressures required to distend the vein were recorded. Samples of $S V$ were taken for microscopical analysis just before we performed the anastomosis.

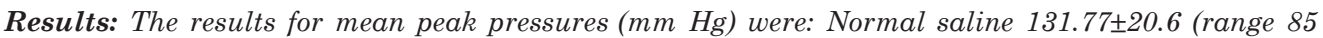
to $199 \mathrm{~mm} \mathrm{Hg}$ ); and Papaverine mixed blood solution, $56.4 \pm 2.1$ (range 40 to $90 \mathrm{~mm} \mathrm{Hg}$ ); P<0.001, (Pap mixed blood solution versus normal saline); The results of histological study for endothelial injury were: Normal saline, $52.5 \%$; Papaverine mixed blood solution, 20\%; (P<.02, untreated versus Pap mixed blood solution).

Conclusions: Intraluminal use of Papaverine mixed heparinized blood solution during vein harvesting requires low distension pressure and improves endothelial coverage compared with the use of heparin mixed normal saline.
\end{abstract}

(Cardiovasc. j. 2011; 4(1): 3-7)

\section{Introduction:}

Saphenous vein continues to be the most common conduits for CABG surgery, despite the widespread use and superior patency of the internal mammary artery and other arterial conduits. However, the long-term patency of saphenous vein grafts is low. The occlusion rate in the first year is $15 \%$ to $26 \% .1,2$ By 10 to 12 years, approximately $50 \%$ of saphenous vein grafts are occluded, ${ }^{3,4}$ and of those still patent, $50 \%$ showed angiographic luminal irregularity or narrowing. ${ }^{5}$

Morphological examination of venous grafts from reoperation or autopsy suggests three different modes of occlusion. ${ }^{1}$ In the first month after operation, occlusion is usually due to thrombosis related to faulty surgical technique. Between 1 month and 1 year, graft occlusion is due to intimal proliferation and medial fibrosis. Beyond 1 year, atherosclerosis is the most common cause of graft occlusion.
There is abundant experimental evidence that the use of high-pressure distension to overcome venospasm during harvesting causes endothelial cell loss and medial damage. ${ }^{6}{ }^{7}$ Endothelial cell loss denudes the surface of the intima, causing deposition of platelets and fibrin, which predisposes to enhanced lipid uptake by the vein wall, ${ }^{8}$ increased intimal hyperplasia, ${ }^{9}$ and reduced patency, at least in the short term. ${ }^{10}$ Pharmacological relaxation of the saphenous vein has been recommended to reduce spasm and obviate the need for high-pressure distension. ${ }^{11}$ Papaverine is the most commonly used vasodilator. However, there is evidence that papaverine used intraluminally may damage the endothelium due to its acidic $\mathrm{pH}^{12}$ and may reduce prostacyclin production in the vein wall.

We developed a simple technique of applying the solution intraluminally to the saphenous vein

Address of Correspondence : Dr. Mohammad Fazle Maruf, Assistant Professor, Cardiothoracic Surgery, Chittagong Medical College, Chittagong 
during harvesting. ${ }^{13}$ In our experience of clinical use, this technique appeared to provide a relaxed venous conduit for grafting. However, we had not quantified the degree of relaxation or shown that the quality of the graft conduits was improved. We therefore set out to study the effects of papaverine mixed blood on the distension pressure required to prepare the saphenous vein for grafting, endothelial morphology and coverage, of the vein wall.

\section{Methods: \\ Patients}

150(One hundred fifty) consenting patients who were undergoing coronary bypass graft surgery were prospective nonrandomized to receive papaverine mixed blood solution Group $\mathrm{A}, \mathrm{n}=70$ and heparin mixed normal saline Group $=\mathrm{B}, \mathrm{n}=80$ for distension of saphenous vein during harvesting of the long saphenous venous conduit. The protocol was approved by the institutional protocol and ethical committee of national institute of cardiovascular diseases and hospital.

Whenever possible a single long segment of great saphenous vein was prepared and removed from the leg by surgical technique. The pressure used during distension and testing of the vein was measured with a pressure transducer connected to a monitor \& or JVP measuring scale. The distending pressure used was the minimum judged necessary by the surgeon in each instance to overcome spasm and to distend the vein adequately for grafting. Pressure was recorded continuously while the vein was harvested, flushed, and distended. The peak pressure was read from the pressure tracing, and the mean pressure was calculated from the area under the pressure curve. After harvesting, all veins were stored in autologous heparinized blood.Within 15 minutes of securing the venous conduit a small segment of vein was preserved and fixed in 10\% formalin and send for histopathologiical examination to see the endothelial injury.

\section{Dilator Solutions}

All solutions were prepared in the operating room using room temperature normal saline containing $1.6 \mathrm{U} / \mathrm{mL}$ heparin. Papaverine solution was made by adding $120 \mathrm{mg}$ papaverine hydrochloride to 100 $\mathrm{mL}$ of normal saline mixed autologous blood $(1.2 \mathrm{mg} / \mathrm{mL})^{12}$ (Table-I).
Table-I

Components and Composition of Papaverine mixed blood Solution

\begin{tabular}{lc}
\hline Component & Volume, $\mathrm{mL}$ \\
\hline Papaverine $30 \mathrm{mg} / \mathrm{mL}$ & 2.0 \\
Sodium bicarbonate 8.4\% & 0.2 \\
Heparin 1000 U/mL & 0.5 \\
Normal saline & 50 \\
Autologus blood & 50 \\
\hline
\end{tabular}

Distension Technique

The saphenous vein was exposed via a short incision at the ankle, and a metal cannula was inserted for injection of the dilator solution.In group-A a 50-mL syringe containing papaverine mixed blood solution was attached to the cannula with the use of a short extension tube. ${ }^{13}$ From 1 to $2 \mathrm{~mL}$ of solution was then injected into the vein and also applied topically as a spray onto its surface with the use of a separate syringe. As the vein was progressively exposed, papaverine mixed blood solution was again applied topically as a spray onto its surface of the vein. Thus, the vein was exposed both internally and externally to the vasodilators in optimal concentrations. After removal from the leg, the vein was distended with papaverine mixed blood solution. In group-B saphenous veins were distended in same manner with heparin mixed normal saline. The prepared veins of both groups were stored in heparinized blood.

\section{Vein Samples}

Two samples of vein were obtained for morphological and microscopical analyses. The first sample (control sample) was obtained immediately after the vein was exposed. The second sample (prepared sample) was obtained from the proximal end of the vein when it was trimmed to length before construction of the aortic anastomosis.

\section{Microscopy}

All samples of vein collected during the operation were preserved and fixed by immersion in $1.2 \%$ glutaraldehyde. Immediately after the second sample was obtained, the samples were sent for histopathologiical examination to see the endothelial injury.

\section{Statistical Analysis}

Unpaired students't' test was used for statistical analysis of the distension pressures, $\chi^{2}$ analysis was used for statistical analysis of the endothelial injury. All values are given as mean \pm SEM. A probability value of $<.05$ was considered statistically significant. 


\section{Results}

Patient characteristics are given in Table 2. Age and sex distributions in the three groups were similar $\left(P=.201,{ }^{2}\right.$ analysis $)$, as was the number of grafts per patient $(P=.5)$. There were no significant differences in the distribution of the two treatments among the four harvesting surgeons $\left({ }^{2}=6.21, P=.4\right)$.

\section{Table-II}

Patient Characteristics

\begin{tabular}{lcc}
\hline & $\begin{array}{c}\text { Group-A } \\
\text { Untreated } \\
(\mathrm{n}=80)\end{array}$ & $\begin{array}{c}\text { Group-B } \\
\text { Papaverine } \\
\text { mixed blood } \\
(\mathrm{n}=70)\end{array}$ \\
\hline Age, y & $57.6 \pm 1.88$ & $57.9 \pm 2.50$ \\
Male, $\mathrm{n}$ & 72 & 60 \\
Female, $\mathrm{n}$ & 8 & 10 \\
Grafts per patient, $\mathrm{n}$ & 3.3 & 3.1 \\
\hline
\end{tabular}

\section{Distention Pressures}

Satisfactory measurements of distension pressure were obtained in 146 patients. The average peak pressure reached during surgical preparation in the group receiving Normal saline treatment (Group-B, n=80), was $131.77 \pm 20.6 \mathrm{~mm} \mathrm{Hg}$ (range,
85 to $199 \mathrm{~mm} \mathrm{Hg}$ ). In the papaverine mixed blood solution group(Group-A, $\mathrm{n}=70$ ), the average mean pressure was $56.4 \pm 2.1 \mathrm{~mm} \mathrm{Hg}$ (range, 40 to 103 $\mathrm{mm} \mathrm{Hg}$ ). The pharmacological treatment groups(group-A) had a significantly lower average distension pressure than the normal saline group (group-B) $(P<.001)$ Table-III.

\section{Endothelial injury}

Satisfactory samples for toluidine blue staining were obtained from 147 patients before preparation (control samples) and 149 patients after preparation (prepared samples). Fig.-1 shows typical appearances of well-preserved and damaged areas. Scanning microscopic photograph of en face preparations confirmed the appearances of satisfactory preservation and endothelial loss. Typical scanning microscopic photograph of wellpreserved and damaged intima are shown (Fig.-1).

The number for endothelial injury in the (Fig.-1) The normal saline treated group- $\mathrm{B}(\mathrm{n}=80)$ had 42 $(52.5 \%)$ of endothelial injury of the Saphenous vein conduit,on the other hand the papaverine mixed blood solution treatment group-A $(n=70)$ had $14(20 \%)$ of endothelial injury of the Saphenous vein conduitd. The papaverine mixed blood solution group had significantly greater endothelial coverage(less injury) than the normal saline treated group $(\mathrm{P}<.02)$. Table-III.

Table-III

Table of peak distension pressures. \& endothelial injury.

\begin{tabular}{llll}
\hline $\begin{array}{l}\text { Distension } \\
\text { Pressure }\end{array}$ & $\begin{array}{l}\text { Papaverine mixed } \\
\text { Blood solutiom N=70 } \\
\text { Group-A }\end{array}$ & $\begin{array}{l}\text { Heparinized } \\
\text { Normal saline N=80 } \\
\text { Group-B }\end{array}$ & $\begin{array}{c}\text { P } \\
\text { values }\end{array}$ \\
\hline Mean pressure (mm Hg) (Mean $\pm \mathrm{SE})$ & $56.4 \pm 2.1 \mathrm{~mm} \mathrm{Hg}$ & $31.77 \pm 20.61 \mathrm{~mm} \mathrm{Hg}$ & $<.001$ \\
Endothelial injury, n (\%) & $14(20 \%)$ & $42(52.5 \%)$ & $<.02$. \\
\hline
\end{tabular}
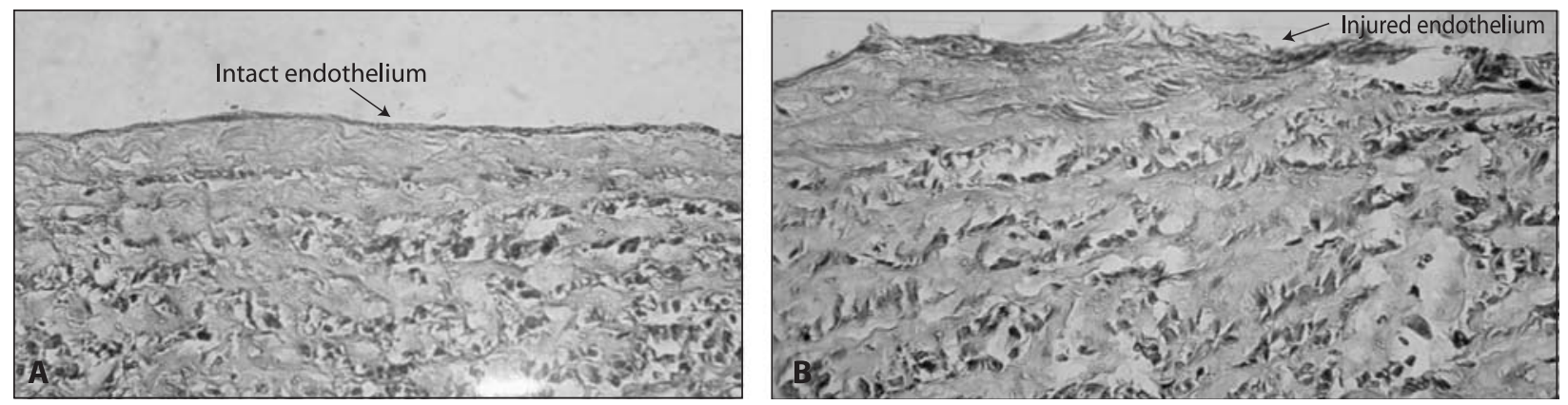

Fig.-1: A Scanning of microscopic photograph of saphenous vein of well-preserved intact endothelium with low pressure distension. B, scanning of microscopic photograph of saphenous vein damaged by high-pressure distension. Endothelium has been lost, exposing the subendothelial connective tissue and smooth muscle fibers. 


\section{Discussion:}

The present study showed that the distension of the venous conduit with papaverine mixed blood solution significantly reduced the pressure required to overcome spasm in vein grafts. The papaverine treated vein grafts showed significantly greater endothelial coverage than did normal salinetreated grafts.

If the endothelium is lost during harvesting, the denuded areas become covered by regenerated endothelium after 1 to 2 weeks. ${ }^{22}$ However, this neoendothelium is laid over a carpet of platelets and fibrin that has been deposited on the thrombogenic basement membrane. Later, this thrombus is replaced by proliferating smooth muscle cells. Platelets are known to release various factors that are implicated in the development of intimal hyperplasia, which, if progressive, may lead to graft occlusion. A variety of growth factors are involved in endothelial segmentation and subsequent intimal hyperplasia. ${ }^{23}$ Thus, preservation of the intima is vital to graft integrity.

The present study has confirmed the findings of others ${ }^{7,8}$ that high-pressure distension during preparation damages vein grafts. In addition, we have shown that by using a powerful vasodilator solution, it is possible to reduce the level of distension pressure required to prepare a vein graft and thereby produce a graft with superior structural integrity. However, it remains to be proved that the better-quality graft will have longer patency.. The fact that vein grafts of primates distended at high pressure have an increased uptake of lipid from the plasma 7 months later suggests that the late patency would also be reduced. ${ }^{8}$ However, until the results of a long-term study of the patency of distended and nondistended vein grafts are available, this question will remain open. In the meantime, we believe that there is sufficient circumstantial evidence that overdistended vein grafts are damaged grafts and that given the poor long-term results of saphenous vein grafts, it is preferable to implant an undamaged vein graft than a damaged one. The papaverine mixed blood solution technique is simple to use, reduces the damage to vein grafts assessed by structural measure, and therefore should be a useful adjunct to coronary artery bypass graft surgery.
High distension pressure has been shown to cause loss of endothelium. The excessive tension in the vein wall causes separation of endothelial cells, which then contract and are easily washed away when the graft is perfused. Extremes of temperature, $\mathrm{pH}$, and osmolarity in the storage solution can also have similar effects on the endothelium. ${ }^{14}$ High distension pressures can also cause loss of high-energy compounds from the vein wall. $^{12}$

In the present study, the peaks of distension pressure generated by the syringe were maintained for only a few seconds at a time, but this would be sufficient to disrupt the medial smooth muscle and to stretch the intima so that the endothelial cells separate, contract, and are able to be removed after perfusion of the graft. The damaged vein graft samples were not exposed to the flow of blood, but we observed under the microscope that gentle irrigation of a damaged vein was sufficient to dislodge the separated endothelial cells. The mean pressure measured was derived from all episodes of distension and quantified the entire damaging insult. A higher mean pressure is the result of higher peaks being reached during each episode of distension and thus indicates a greater potential for damage to the vein wall.

The endothelium was best preserved with papaverine treatment. A likely reason for this would be the lower peak distension pressure in this group, which reduced shedding of endothelial cells

Many other factors are involved in damage to the endothelium other than physical trauma during harvesting and preparation. Another factor could be the provision of a physiological $\mathrm{pH}$, papaverine $\&$ normal saline are acidic but when these are mixed with blood \& small amout bicarbonate its $\mathrm{pH}$ comes nearly 7 to 7.4 . which is lacking in unbuffered normal saline (approximate $\mathrm{pH}$ 5); Most important are the storage conditions for the vein between harvesting and grafting, which may subject the vein to ischemic damage..$^{15}$ Our results suggest that storage conditions also need to be improved to enhance the endothelial coverage and energy preservation in vein grafts.

The vast majority of ATP in the saphenous vein wall resides in the smooth muscle cells of the media. ${ }^{6}$ This is a consequence of the fact that the 
most common cell type in the vein wall is the smooth muscle cell. Angelini et $\mathrm{al}^{6}$ have shown that high distension pressure causes a reduction in the ATP content in the vein wall, which is therefore in large part a reflection of medial damage rather than loss of endothelium. Loss of ATP is presumably caused by contraction of the smooth muscle against high distending pressure. We found that in terms of energy status, pharmacologically treated veins were better preserved than the untreated veins.

Papaverine is the vasodilator most described in the literature. Previous studies have suggested that the use of solutions containing papaverine for distension and storage $\mathrm{e}^{11,12}$ or for perivenous infiltration or topical application ${ }^{15}$ during vein harvesting have resulted in better histological appearance of the grafts. However, there is the possibility that papaverine used intraluminally may damage the endothelium due to its acidic $\mathrm{pH} .{ }^{12}$ Therefore, in the present study to avoid endothelial damage and the risk of systemic hypotension, in the papaverine-treated group, papaverine was applied after buffering by mixing with autologus blood \& bicarbonate solution.

In our clinical experience, no episodes of clinically significant systemic hypotension attributable to the use of papaverivne mixed blood solution were observed when the solution was used as described.

\section{Conclusion:}

We reached three conclusions. First, all types of surgical preparation and storage cause some loss of the endothelium and a decrease in the energy status of the vein wall. Second, treatment of saphenous veins with vasodilators allows the use of lower distension pressure during harvesting, reduces the loss of endothelium. Third, topical and intraluminal use of papverine mixed blood solution improves endothelial coverage compared with the intraluminal use of heparinized normal saline.

\section{Footnotes}

Address reprint requests to Dr.Mohammad Fazle Maruf, Assistant professor, Department of Cardiothoracic Surgery, Chittagong Medical College.

\section{References:}

1. Bourassa MG, Campeau L, Lesperance J, Grondin CM. Changes in grafts and coronary arteries after saphenous vein aortocoronary bypass surgery: results at repeat angiography. Circulation 1982; 65(suppl II):II-90-II-97.
2. FitzGibbon GM, Leach AJ, Keon WJ, Burton JR, Kafka HP. Coronary bypass graft fate: angiographic study of 1,179 vein grafts early, one year, and five years after operation. J Thorac Cardiovasc Surg 1986; 91:773-778.

3. Campeau L, Enjalbert M, Lesperance J, Vaislic C, Grondin CM, Bourassa MG. Atherosclerosis and late closure of aortocoronary saphenous vein grafts: sequential angiographic studies at 2 weeks, 1 year, 5 to 7 years, and 10 to 12 years after surgery. Circulation 1983; 68(suppl II):II-1-II-7.

4. Lytle BW, Loop FD, Cosgrove DM, Ratliff NB, Easley K, Taylor PC. Long-term (5 to 12 years) serial studies of internal mammary artery and saphenous vein coronary bypass grafts. J Thorac Cardiovasc Surg 1985; 89:248258.

5. Grondin CM, Campeau L, Lesperance J, Enjalbert M, Bourassa MG. Comparison of late changes in internal mammary artery and saphenous vein grafts in two consecutive series of patients 10 years after operation. Circulation 1984; 70(suppl I):I-208-I-212.

6. Angelini GD, Passani SL, Breckenridge IM, Newby AC. Nature and pressure dependence of damage induced by distension of human saphenous vein coronary artery bypass grafts. Cardiovasc Res 1987; 21:902-907.

7. Cambria RP, Megerman J, Abbott WM. Endothelial preservation in reversed and in situ autogenous vein grafts: a quantitative experimental study. Ann Surg 1985; 202:50-55.

8. Boerboom LE, Bonchek LI, Kissebah AH, Werner PH, Pepper JR, Olinger GN, Korns ME, Garancis JD. Effect of surgical trauma on tissue lipids in primate vein grafts: relation to plasma lipids. Circulation 1980; 62 (suppl I): I-144-I-147.

9. Ramos JR, Berger K, Mansfield PB, Sauvage LR. Histologic fate and endothelial changes of distended and nondistended vein grafts. Ann Surg 1976; 183:205228.

10. Angelini GD, Bryan AJ, Williams HM, Morgan R, Newby AC. Distention promotes platelet and leukocyte adhesion and reduces short-term patency in pig arteriovenous bypass grafts. J Thorac Cardiovasc Surg 1990; 99:433-439.

11. Adcock OJ, Adcock GL, Wheeler JR, Gregory RT, Snyder SJ, Gayle RG. Optimal techniques for harvesting and preparation of reversed autogenous vein grafts for use as arterial substitutes: a review. Surgery 1984; 96: 886-894.

11. Roberts AJ, Hay DA, Jawahar LM, Mehta P, Roy L, Faro RS, Knauf DG, Alexander JA. Biochemical and ultrastructural integrity of the saphenous vein during CABG: preliminary results of the effect of papaverine. J Thorac Cardiovasc Surg 1984; 88: 39-48.

12. He GW, Rosenfeldt FL, Angus JA. Pharmacological relaxation of the saphenous vein during harvesting for coronary artery bypass grafting. Ann Thorac Surg 1993;55:1210-1217

13. Constantinides $\mathrm{P}$, Robinson M. Ultrastructural injury of arterial endothelium, 1: effects of $\mathrm{pH}$, osmolarity, anoxia, and temperature. Arch Pathol 1969; 88: 99-105

14. LoGerfo FW, Quist WC, Crawshaw HM, Haudenschild C. An improved technique for preservation of endothelial morphology in vein grafts. Surgery 1981; 90: 1015-1024. 